\title{
Motivational Intensity as the Mediator of Orientation and Attitudinal with the Achievement of Chinese Language among the Preservice Teachers
}

\section{Fonny Hutagalung}

Dr., University of Malaya, Lembah Pantai Road, 50603 Kuala Lumpur, Malaysia, fonny@um.edu.my

\section{Fong Peng Chew}

Dr., correspondence author, University of Malaya, Lembah Pantai Road, 50603 Kuala Lumpur, Malaysia,fpchew@um.edu.my

\section{Tan Chor Ter}

Mr., University of Malaya, Lembah Pantai Road, 50603 Kuala Lumpur, Malaysia, tchorter@gmail.com

This research is about the importance of the expected achievement of preservice Chinese language teachers based on their orientation, attitude, and motivation in teaching education programs. The cluster sampling and random sampling methods were implemented to select the samples from 16 Institute of Teacher Education Malaysia (IPGM). A total of 389 respondents were selected in the study and the data was analysed by using Smart PLS 3.0 software. This study applied a two-stage analysis in a reflective-formative way to analysis the multidimensional constructs on the learning situation. The findings showed a significant positive relationship of teachers' integration orientation, instrumental orientation, and attitudes towards learning situations with their Chinese language achievements. The motivation of intensity acted as a mediator factor and showed a partial positive effect in the relationship between integration orientation, instrumental orientation and attitudes towards learning situation with Chinese language achievement. It is due to relationship between motivation and positive attitude as well as the orientation of integration has shaped the integration motivation in the socio-learning model. Thus, the results of the study can be used as a reference source of multivariate relationship study between the orientation, attitudes, motivation, and achievement of future refractive-formative research.

Keywords: intensity motivation, orientation, attitude, Chinese language, preservice teachers, language learning

Citation: Hutagalung, F., Chew, F. P., \& Ter, T. C. (2020). Motivational Intensity as the Mediator of Orientation and Attitudinal with the Achievement of Chinese Language among the Preservice Teachers. International Journal of Instruction, 13(4), 937-956. https://doi.org/10.29333/iji.2020.13457a 


\section{INTRODUCTION}

High quality teachers are effective in promoting national education. According to the report of the Malaysian Education Development Plan 2012-2025 (KPM, 2015), high quality teachers' education which produces quality teachers, can enrich the country's education and provide effective education for every student in the school. To achieve this goal, the orientation and attitudinal of the preservice teachers in the teacher's education institute is important to be studied.

According to Gardner (1985; 2001), the strength, desire, and interest are the motivating force in the language learning. The probability of success will be likely high if the attitudes toward learning situations and learning orientations are positively associated with high motivation (Gardner, 2006; 2001; 1985) and vice versa. At the same time, the relationship between motivation and positive attitude and integration orientation has shaped the integration motivation in the socio-learning model (Gardner 1985; 2001, 2006). For this reason, motivational intensity indirectly has become one of the factor that influences an individual's attitude and orientation to develop his or her ability to reach great achievements.

Motivational intensity is the actual drive of an individual to achieve his or her objectives. The motivational intensity is guided by the difficulty level of the task, which doesn't reach beyond the upper limit set by the potential motivation. Intensity can be seen in the concentration and the force to pursue a goal (Zhou \& Xiu, 2015). Typically, there is a close relationship between intensity and the expectation of a desired result. Intensity, or motivational force is influenced by the individual's orientation and attitude towards the effort to yield a certain result.

This topic rarely found in recent studies in Chinese education in Malaysia. Therefore, it is necessary and significant to conduct a study on motivational intensity to examine the willingness of the preservice teachers in learning Chinese language. This gap needs to be filled to find solutions to increase the willingness of preservice teachers to learn Chinese language.

This study contributes to the discussion on the topics based on the structural model of the final study that can serve as a guidance to fill in the gaps between Chinese culture and education programs. This model can be used as a reference to provide more effective course activities in motivating and changing attitudes, interests, aspirations and objectives among the preservice teachers in Chinese language education and culture.

\section{Problem Statement}

Continuous changes and improvement in the education system is a challenge for preservice teachers in the teachers' education program. The transformation of the Primary School Curriculum Integrated Education System and the Secondary Curriculum to the Primary School Curriculum and the Secondary Syllabus Curriculum in 2013, showed that education system is constantly updated in line with current and future developments. As such, preservice teachers in the teachers' education program should have the self-awareness and willingness to accept future changes. However, Malaysia 
National Review Report on Education for All (2015) stated that compared with the teachers' education development in more developed country, Malaysian education is still lagging for some reasons. First, the school teachers are incapable to provide quality education. Second, Malaysian teachers did not learn the professional competencies in teacher's education throughout the career. Third, their teaching content were out of date, lack of advance and critical thinking skills. Finally, they were unable to transfer the knowledge to students (Clandinin \& Husu, 2017).

Regarding this issue, Macalister (2017), Mahmud, Nasri, Samsudin (2018) argued that the content of the teachers' education program are limited and inadequate for developing the content of the subject in depth. Furthermore, the pedagogical content for the preservice teachers put too much emphasis on the discussion and it is lack of exposure. The incompatibility of the content in the teachers' education program has caused the inability of teachers to develop their skills and expertise. Therefore, the content of the teachers' education program should be adjusted with the attitude and motivation of the preservice teachers in the learning process.inter

Efforts to produce a professionally trained preservice teachers are the responsibility of every lecturer in the teachers' education program. Research from Chen and Yi (2019) showed that preschool teachers had difficulty in teaching reading skills to non-native speakers, due to the inability of the children to pronounce words with the correct intonation according to Hanyu Pinyin, which consequently made them unable to speak correctly and fluently. This is due to poor comprehension, limited vocabulary and confusion between alphabet pronunciation and Hanyu Pinyin pronunciation problems of the children while reading. On the contrary, the preservice teachers who are non-native speakers are facing the problem in reading skills that cause them facing difficulty in teaching (Lam, Yau, Yeo, Chew, Lee \& Lee, 2006). The lack of reading skills among preservice teacher has affected the beauty and art of the language, which will cause lack of interest among students towards Chinese language.

The study of Ng, Wong, Guek, Lim \& Tan (2017) also stated that Chinese language preservice teachers from Duiwai Hanyu Postgraduate Education Diploma Program (Chinese as a foreign language) from Chinese universities are also having trouble reading and writing Chinese language. Preservice teachers are having trouble reading words with the right intonation, and with limited vocabulary. Chinese language preservice teachers had to combine the use of Malay language in teaching and learning activities. The preservice teachers are not able to actively discuss with the students and only use short sentences. Weaknesses in mastery of Chinese language among preservice teachers will negatively impact the students. With poor Chinese language skills, the preservice teachers will likely use improper grammar and pronunciation. Unfortunately, the students will most likely imitating the teacher's mistakes as they think that teachers is always right.

The weaknesses in mastery of Chinese language is related to the complexity of Chinese language system. Study from Li (2019) found that Chinese characters writing system is different from the English alphabet. The uniqueness of Chinese character is found in three elements, namely phonology, semantics and morphology. Interestingly, 
morphology is the hardest skill to be mastered. Chinese character writing system is known as the logographic writing system because Chinese characters are made of lexical morphology, with about $80 \%$ to $90 \%$ of Chinese characters are made up of two components: (i) semantic radical words, which some of the words carries the meaning of the words (ii) phonetic radicals, which is the pronunciation of words. Students are not able to recognize Chinese words when reading and writing because each Chinese word is an ideogram language that cannot be spelled alphabetically. As such, the attitude towards the Chinese language among preservice teachers will determine whether they accept or reject Chinese language (Gardner \& Lambert, 1972). If the preservice teachers have a positive attitude towards the Chinese language, they will be interested and value the Chinese language and thus would change their behaviour as they seek to improve their performance (Linyi Technician Institute, 2017). It will also improve their Chinese language and confidence to achieve success in the teacher's education program (Zhang, 2018).

However, the preservice teachers do not necessarily succeed in the teacher's education program if they do not have a positive attitude, learning orientation and motivation. Wabule's (2017) study noted that attitude and motivation are two factors that determine the success of preservice teachers in their future teacher's education program. Highly motivated preservice teachers are actively involved in learning and make the learning process effective, rewarding and enjoyable. On the other hand, when teachers lack motivation, they feel lost in direction and objective which make them feel helpless and tired of learning (Deci \& Ryan, 2000). Furthermore, Gardner (1985, 2001) emphasized that attitudes toward teaching situations and negative learning orientations will undermine motivation in the learning process. Therefore, positive attitudes, learning orientations and motivations directly change their behaviour in teacher's education program.

In the social learning model (Gardner, 1985, 2001) and the psychological and social models (Gardner \& Lambert, 1972), motivation is a factor that determines the success of language learning process, while attitude and orientation of individuals will influence their self-motivation to achieve the learning intention. According to the findings of Gardner (1985, 2001), attitudes toward learning situations, integration and instrumentaloriented motivations, each influencing one's interest, and desire that will determine different achievements in language learning. As such, attitudes towards the situation, learning orientation and motivation of Chinese language preservice teachers are elements that will differentiate individual in the actual learning process.

Research done by Khalid (2016); Khansir, Jafarizadegan and Karampoor (2016) showed that instrumental orientation and integration of language learning is related to socioeconomic status. These studies show that both orientations change the attitudes towards language and motivation towards the mastery of Mandarin, English and dialects. Liu (2017) explained that foreign language students with integration orientation motivation are more likely to interact with native speakers and are interested in foreign culture. These students showed a better mastery of foreign languages than those who are instrumental motivation students. On the contrary, other studies suggest that integration 
orientation motivation does not necessarily enhance the positive achievement of foreign languages learning (Song \& Pornsima, 2017).

Previous studies from Gu and Cheung (2016); Chai, Wong and King (2016); Chiang (2018); Hu (2019) indicated that integration and instrumental oriented motivation are factors that determine the success of Chinese language mastery. Nevertheless, the results of these studies are inconsistent with different learning environments at overseas and there are no local studies yet conducted explaining the differences in factors involved in Chinese language learning process among Chinese language preservice teachers in Malaysia. Thus, there is a need to conduct a research on the relationship between integration orientation, instrumental orientation, attitude with learning situations and motivation among preservice teachers to determine the validity of influencing factors of individual differences in Chinese language mastery.

However, there are also studies that show that the choice of the teaching profession is an expectation of predicting the success of a preservice teacher based on the reasons for choosing a teaching profession. The report "Why people choose teaching: A scoping review of empirical studies, 2007-2016", by Fray and Gore (2018) explains that teaching career choice is associated with altruistic motivation, intrinsic motivation and extrinsic motivation. Altruistic motivation refers to the characteristics of individuals who are willing to help, helpful and love others. Intrinsic motivation shows that they love and enjoy teaching the subject they like, achievement process, develop new knowledge and engage in activities, while extrinsic motivation shows preservice teachers focus on good lifestyle, earn good income, shorter working time and good job opportunities abroad. This study has shown that the motives of each preservice teacher are different when making the choice to become a teacher.

Furthermore, the theory of self-determination (Deci \& Ryan, 2000), motivation is a force for self-defence mechanism and perseverance in the pursuit of learning objectives. Intrinsic motivation refers to a person engaging in an activity with high commitment and satisfaction in the process of achievement, while extrinsic motivation refers to the purpose of engaging in an activity solely to earn rewards. Generally, preservice teachers experience a wide range of motivations to develop their work ethic and selfdetermination in the educational process of the teaching profession (Sinclair, 2008) and the purpose of selecting a teaching profession (Gao \& Trent, 2009; Kyriacou \& Kobori, 1998). This is due to the motivation of the preservice teachers is constantly changing based on their background, confidence, social culture and future professional development opportunities (Gao \& Trent, 2009; Malmberg, 2006; Watt \& Richardson, 2008).

However, there are also studies that showed that an atmosphere of autonomous support can change extrinsic motivation to intrinsic motivation (Niemiec \& Ryan, 2009). The study suggested that students' basic psychological needs regarding the autonomy, competence, and relatedness that facilitates students' autonomous self-regulation for learning, academic performance, and wellbeing must be supported by the teachers. Furthermore intrinsic motivation positively influence academic achievement because it reflects a sense of etermination and personal interest rather than external pressure. 
(Taylor, Jungert, Mageau, Schattke, Dedic, Rosenfield \& Koestner, 2014). To use various learning strategies, the learners need to have autonomous intrinsic motivation. Students who are intrinsically motivated will be proactive in seeking out useful resources that could help with the learning process (Zhang, Lin, Zhang and Choi, 2017), whereas, the extrinsic motivation negatively influences achievement (Karlen, Suter, Hirt \& Merki, 2019). Students with intrinsic motivation will achieve higher academic achievement through perseverance effort, to write the paper and to be less extrinsically motivated.

Based on the findings of previous research, it can be concluded that intrinsic motivation can develop self-ability such as commitment, interest, learning ability and deepening knowledge of the subject they are interested in. This means that the atmosphere of autonomous support learning environment will elevate intrinsic motivation. High levels of intrinsic motivation can positively enhance the Chinese language proficiency of the preservice teachers. Therefore, the study should test the significance contribution of intrinsic and extrinsic motivation towards mastery of Chinese language and language skills, which could be used to help solve the problem of Chinese language mastery among Chinese language preservice teacher.

Therefore, the objectives of this study are to answer the following questions:

1. Is motivational intensity is a mediating factor between integration orientation and Chinese language achievement?

2. Is motivational intensity is a mediating factor between instrumental orientation and Chinese language achievement?

3. Is motivational intensity is a mediating factor between attitudes towards learning situations and Chinese language achievement?

The following hypotheses are used to answer these research questions:

H1: Motivational intensity serves as a mediating factor between integration orientation and Chinese language achievement.

$\mathrm{H} 2$ : Motivational intensity serves as a mediating factor between instrumental orientation and Chinese language achievement.

H3: Motivational intensity serves as a mediating factor between attitudes towards learning situations and Chinese language achievement.

\section{Research Conceptual Framework}

This study used social psychological models theory (Lambert, 1975) and sociocultural models (Gardner, 1985; 2001) to study the relationship between integration orientation, instrumental, attitude to learning situations and motivation intensity with Chinese language achievement. In addition, self-determination was selected to identify the relationship of intrinsic and extrinsic motivation with achievement in Chinese language.

According to motivational intensity theory, the difficulty of the task and the reward of successful accomplishment will results in the difference of effort investment by 
individual. There are important distinction between potential motivations and the maximum amount of effort a person that will exert, because of the demand from the task (Brehm \& Self, 1989; Wright, 2008).

According to Brehm \& Self (1989), people tend to do a task with low level of difficulty, which based on the conservation principle that assumes that people will aim to save resources. The theory predicts that people will not try to do a difficult task regardless of the reward provided (Richter, 2013; Wright, 2008).

The conceptual framework of this study is presented in Figure 1, adapted from the social psychology research model (Gardner \& Lambert, 1972) and the psychological learning model (Gardner, 2001). Both models identified that orientation and attitude as independent variables, motivational intensity as a mediating factor and academic achievement as dependent variable and have a positive relationship. In Figure 1, motivational intensity is a mediating factor between integration orientation (ORI), instrumental orientation (ORT) and attitude toward learning (SKP) with Chinese language (CL) achievement among Chinese language preservice teachers. Attitudes toward learning situations are multidimensional constructs consisting of attitudes toward Chinese language, Chinese language teachers and Chinese language education programs.

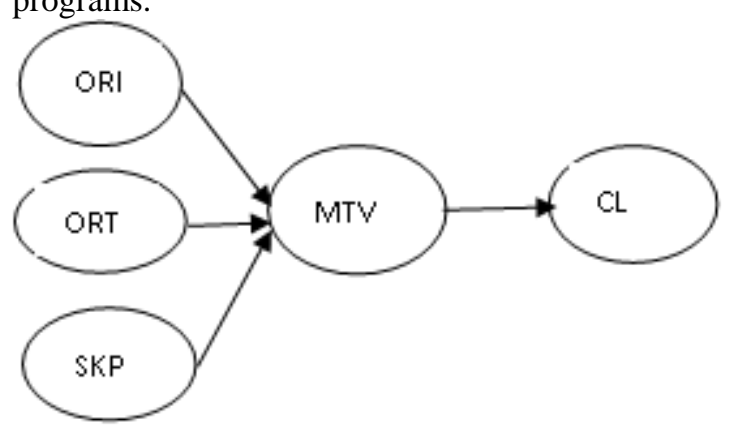

Figure 1

Conceptual Framework of the Study

\section{METHOD}

\section{Research Design}

The design of this study is a non-experimental study known as correlation study. This method was used to enable data collection of integration orientation factors, instrumental orientation, extrinsic motivation, intrinsic motivation, and attitude towards learning situations and sample intensity motivation from a large population simultaneously (Creswell, 2014).

\section{Sample and Sampling Method}

A total of 389 samples were selected from 16 teachers' education institutes nationwide. At the first stage, comparative sampling was used where the population of Chinese language teachers was divided into two groups according to the PISMP and DPLI 
programs. Based on the $95 \%$ confidence level, it is recommended that the sample size be 398 people, that the sample PISMP program is 275 people and DPLI is 123 people.

At the second level, cluster random sampling was used for a large population of preservice teachers, which was scattered in each state and with no individual list (sample frame) to select the sample (Ranjit Kumar, 2011; Cohen, Manion and Morrison, 2005; Sabitha, 2005). Then, the study sample in Peninsular Malaysia was divided into Northern Zone (Perlis, Kedah, Penang and Perak), Central Zone (Kuala Lumpur, Selangor), the Southern Zone (Negeri Sembilan, Melaka and Johor), the eastern zone (Kelantan, Pahang and Terengganu) and East Malaysia (Sabah and Sarawak). Then a group of Chinese language preservice teachers from GPA were randomly selected for the sample.

\section{Instruments of the Study}

The instruments of this study consist of Chinese language tests and a questionnaire. The Chinese language test was used to measure the performance of the Chinese language. The language test consists of 20 questions on Chinese language grammar including phonetics, characters, and vocabulary as well as 20 questions on Chinese culture. Chinese culture comprises aspects of Chinese classical education and philosophy, Chinese language and literature, classical Chinese literature, ancient Chinese science and technology, and traditional Chinese culture. For instance, the question quoted a sentence and ask who the author was; description on a festival and ask what the festival is and so on. The total score for this test is $100 \%$ and the total score of each respondent was categorized into five grades namely grade A $(75 \%-100 \%)$, grade B $(60 \%-74 \%)$, grade C (40\%-59\%), grade D (20\%-39\%) and grade D (0\%-19\%).

The questionnaire is divided into four sections. Part A is the social background of the respondents including gender, race, Chinese language education background and the mother tongue language of the respondents. Whereas Part B is an integrated and instrumental orientation adapted from the questionnaire on language learning motivation (Larisa Niktina, Zuraidah Mohd Don \& Loh, 2016). Examples of the question is "Proficiency in the Knowledge of the Chinese language will be useful for my further studies". Part C is made up of respondents' attitudes towards the modified learning situation of Culture Studies and Motivation in Foreign and Second Language Learning in Taiwan (Ho, 1998), such as the item of "Learning Chinese language is a waste of time", "I feel that my Chinese language teacher is friendly.", "My Chinese language course is useful." Part D is a modified motivational intensity from Motivation, Motivation Intensity, use of Chinese and Self-Rated Chinese Competence (Liu, 2017) such as "I will not stop trying to learn until I reach the skill level in Chinese that I seek" and "I learn Chinese by working on it almost every day". Each item uses a five-point Likert scale of 1 as strongly disagree and 5 as strongly agree. Each respondent is required to answer a set of Chinese language questions within 1 hour and respondents are also required to answer a set of questionnaires after the Chinese language test.

The Chinese language tests and questionnaires in this study has been verified by field experts. A pilot study was conducted at three GPA in Perak involving 99 Chinese 
language preservice teachers. Richardson Kuder Test 20 (KR 20) provides the means for analysing the reliability of Chinese language test items. The results show that the Chinese language test has high reliability $(\mathrm{KR}=.713)$ and is suitable for conducting the Chinese language preservice teacher achievement test. While the alpha coefficient for the questionnaire ranged from .70 to .96 for all constructs and sub-constructs of the study. Therefore, both instruments are suitable for use in future studies.

\section{Demographic of the Respondents}

After data cleaning from isolated cases, 398 preservice teachers were selected in this study. The demographic profile is divided into two programs, namely Postgraduate Degree in Education (PISMP) with 267 respondents (67\%) and Postgraduate Education Diploma (DPLI), with 131 respondents (33\%) with a bachelor's degree in Mandarin as their foreign language from universities in China. All PISMP preservice teachers, 40 men $(15 \%)$ and 227 women $(85 \%)$ are from Chinese ethnicity, with Chinese language qualification from the Malaysian Certificate of Education (SPM), Chinese language as their mother tongue. While DPLI preservice teachers are from Malay ethnicity, 23 men (16\%) and 108 women (84\%), with the passing of Hanyu Shuiping Kaoshi, which is a proficiency examination of Mandarin, Malay language as a mother tongue.

\section{Chinese Language Achievement}

The Chinese language test grades for PISMP preservice teachers showed a $99.63 \%$ passing percentage, grade A was $22.85 \%$, grade B was $51.31 \%$ and grade $\mathrm{C}$ was $25.47 \%$. While the Chinese language test grade for DPLI preservice teachers showed a passing percentage of $73.28 \%$ where grade A was $0 \%$, grade B was $6.88 \%$ and grade C was $66.41 \%$. Furthermore, it was found that $26.72 \%$ of DPLI preservice teachers who failed in grade D were higher than $0.37 \%$ of PISMP preservice teachers who failed the Chinese language test. The findings of this study showed that the Chinese language achievement of PISMP preservice teachers is better than DPLI preservice teachers.

\section{FINDINGS}

This study uses Smart PLS3.0 software to carry out the analysis due to the involvement of reflective and formative constructs. In addition, structural model analysis is performed using Hierarchical Component Models. The use of a two-stage hierarchical model is one way to summarize the number of constructive relationships in the study model and to make the study constructs more understandable (Akter, Wamba \& Hall, 2017; Hanseler, Ringle \& Sinkovics, 2009). The study of Akter et al. (2017) and Becker, Klein \& Wetzels (2012) explain that reflective-formative constructs in the twostage model can solve multicollinearity problems in first-level reflective constructs and collinearity value formative construct indicators.

After conducting an analysis of the measurement model, the latent values of the variables construct integration orientation, instrumental orientation, motivational intensity and achievement of the Chinese language were used as values representing the overall indicators of each construct in the second level model, while the latent value of variables for attitude toward Chinese language, attitude toward the lecturer of Chinese 
language and attitudes towards the educational program are used as values representing the three sub-constructs forming attitudes towards learning situations in the formative constructs of the second level model. Thus, the second-level model analysis is simpler and easier. Subsequent analyzes of the moderator were later performed.

\section{Structural Model Analysis}

Table 1

Pathway Coefficient Analysis

\begin{tabular}{lllll}
\hline Relationship & Beta & SP & $t$-value & $p$ \\
\hline ORI -> MTV INT & .151 & .056 & 2.680 & .007 \\
ORT -> MTV INT & .147 & .049 & 3.025 & .002 \\
SKP -> MTV INT & .416 & .055 & 7.590 & .001 \\
MTV INT -> CL & .252 & .049 & 5.151 & .001 \\
ORI -> CL & .038 & .017 & 2.224 & .026 \\
ORT -> CL & .037 & .014 & 2.663 & .008 \\
SKP -> CL & .105 & .026 & 4.078 & .001 \\
\hline
\end{tabular}

$p<.05$

The results of the study after performing the boostrapping calculations by repeated samples 5000 times are shown in Table 1. Coefficient analysis revealed that each relationship was positively and significantly related to integration orientation $(\beta=.151$, $p<.05)$, instrumental orientation $(\beta=.147, p<.05)$ and attitude toward learning situations $(\beta=.416, p<.05)$ with motivational intensity. In addition, the relationship between motivational intensity with Chinese Language achievement $(\beta=.252, p<.05)$, was positively significant. Furthermore, the relationship of integration orientation $((\beta=$ $.038, p<.05)$, instrumental orientation $(\beta=.037, p<.05)$ and attitude towards learning situations $(\beta=.105, p<.05)$ with Chinese Language achievement were also significantly positive.

Next, the multiple regression value of motivational intensity was $\mathrm{R} 2=.331(33.1 \%)$ which showed high motivational intensity according to Cohen (1988). Motivational intensity variants were explained by integration orientation $(\beta=.151)$, instrumental orientation $(\beta=.147)$ and attitude toward learning situations $(\beta=.416)$. Based on statistical findings, it was found that integration orientation, instrumental orientation and attitude towards learning situations contributed $33.1 \%$ to motivational intensity while $66.9 \%$ was other latent variables that were not examined in this study. The effect sizes of integration orientation (.025) and instrumental orientation (.026) were weak while attitude toward learning (.203) was moderate according to Cohen (1988). The findings of this study showed that attitudes toward learning situations have a positive impact on motivational intensity.

Multiple regression of the Chinese language achievement $\mathrm{R} 2=.063(6.3 \%)$ indicated that it was at a low level (Cohen, 1988). The variants of Chinese language achievement were explained by motivational intensity $(\beta=.252)$. Based on the statistical findings, motivational intensity contributes $6.3 \%$ to Chinese language achievement while $93.4 \%$ was other latent variables that were not examined in this model. The effect size of the motivational intensity (.068) is weak according to Cohen (1988). 


\section{Models of Intensity Motivation between Integration Orientation and Chinese Language Achievement}

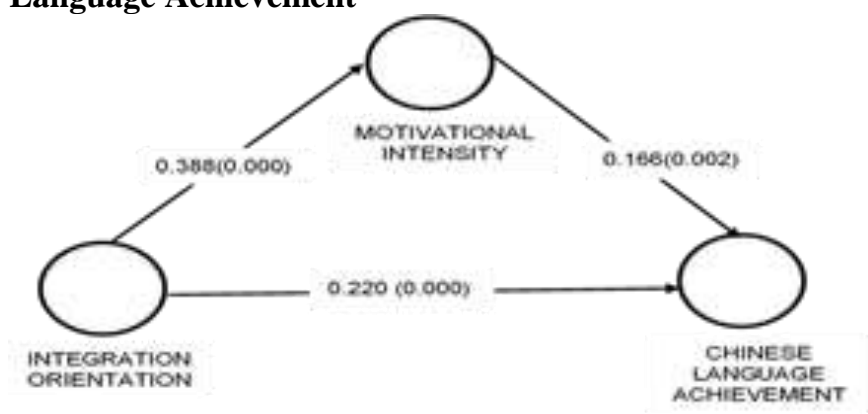

Figure 2

Models of Intensity Motivation between Integration Orientation and Chinese Language Achievement

Table 3

Motivational Intensity Analysis between the Relationship of Integration Orientation and Chinese Language Achievement

\begin{tabular}{|c|c|c|c|c|c|c|c|}
\hline pathway & Relationship & Beta & $S P$ & $t$-value & $p$-value & $95 \%$ significantly & Effect \\
\hline $\mathrm{a}$ & ORI-> MTV INT & .338 & .046 & 8.475 & .000 & & There are \\
\hline b & $\begin{array}{l}\text { MTV INT }->\text { Result } \\
\text { of CL }\end{array}$ & .166 & .054 & 4.052 & .000 & & $\begin{array}{l}\text { indirect effects } \\
\text { The }\end{array}$ \\
\hline$c^{\prime}$ & ORI-> Result of CL & .220 & .053 & 3.143 & $.000 *$ & & intermediary \\
\hline$a \times b$ & $\begin{array}{l}\text { ORI-> MTV INT -> } \\
\text { Result of CL }\end{array}$ & .065 & .023 & 2.809 & $.005 *$ & .024 & $\begin{array}{l}\text { factor as a } \\
\text { complement }\end{array}$ \\
\hline
\end{tabular}

Based on the results of the studies in Figure 2 and Table 3, the results of the indirect effects study showed that the intermediates were significant $(\beta=.338 * .166=.065, p$ $<.05,95 \% C I: .024: .119)$ and 95\% confidence intervals do not include zero (0), indicating that motivational intensity is an intermediate factor influencing the relationship between integration orientation and Chinese language achievement. Therefore, the Ha1 hypothesis was accepted with findings of the study and the motivational intensity has indirect relationship between integration orientations with Chinese language achievement. 


\section{Models of Intensity Motivation between Instrumental Orientation and Chinese Language Achievement}

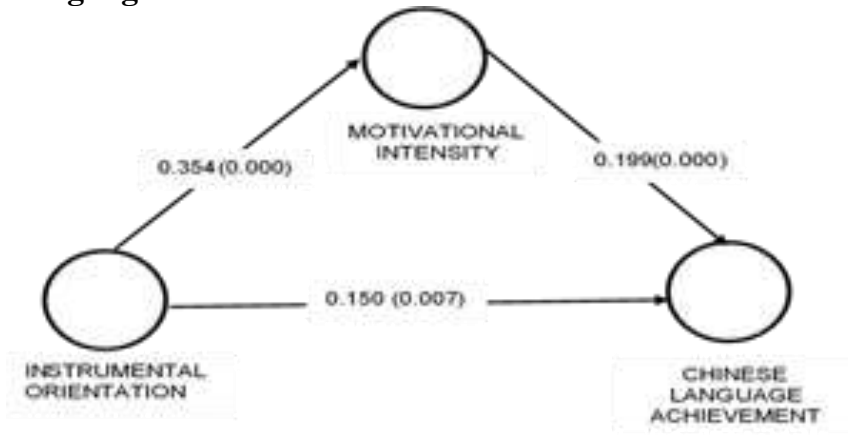

Figure 3

An Intermediate Analysis Model of the Relationship of Instrumental Orientation to Chinese Language Achievement

Table 4

Intermediate Analysis of Instrumental Oriental Relationship with Chinese Language Achievement

\begin{tabular}{llllllll}
\hline Pathway & Relationship & Beta & $S P$ & $t$ value & $p$ value & $\begin{array}{l}95 \% \\
\text { Significantly }\end{array}$ & Effect \\
\hline a & ORT -> MTV INT & .354 & .047 & 7.519 & .000 & & $\begin{array}{l}\text { There are } \\
\text { indirect } \\
\text { effects }\end{array}$ \\
b & $\begin{array}{l}\text { MTV INT -> } \\
\text { Result in CL }\end{array}$ & .199 & .054 & 3.694 & .000 & & The \\
c' & ORT -> Result in & .150 & .056 & 2.692 & $.007 *$ & & $\begin{array}{l}\text { intermediary } \\
\text { factor as a } \\
\text { complement }\end{array}$ \\
\hline
\end{tabular}

Findings in Figure 3 and Table 4, showed that the results of indirect impact indicate that the intermediates were significant $(\beta=.354 * .199=.070, p<.05,95 \% C I: .033: .118)$ and $95 \%$ confidence intervals excluding zero $(0)$, indicating that motivational intensity is an intermediate factor influencing the relationship between instrumental orientation and Chinese language achievement. Therefore, the Ha2 hypothesis is accepted as motivational intensity indirectly affecting the relationship between instrumental orientations with Chinese language achievement. 

Models of motivational intensity between the relationship of attitudes to learning
situations and achievement in Chinese language

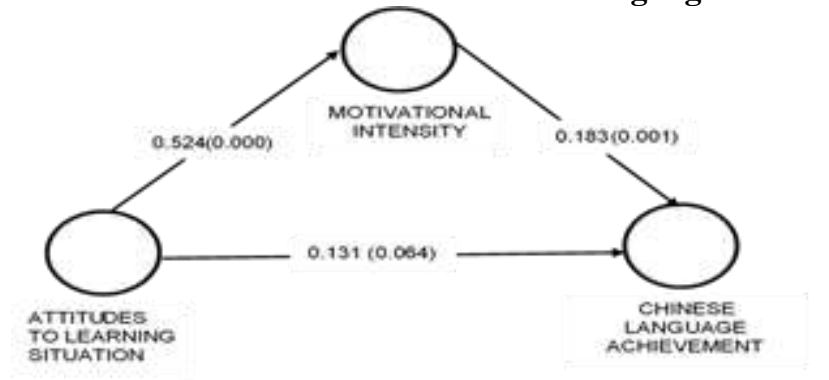

Figure 4

Models of Motivational Intensity between the Relationship of Attitudes to Learning Situations and Achievement in Chinese Language

Table 5

Motivational Intensity Analysis between Attitudes toward Learning Situations and Chinese Language achievement

\begin{tabular}{|c|c|c|c|c|c|c|c|}
\hline Pathway & Relationship & Beta & $S P$ & $t$ value & $p$ value & $\begin{array}{l}95 \% \\
\text { Significantly }\end{array}$ & Effects \\
\hline $\mathrm{A}$ & $\begin{array}{l}\text { MTV INT -> } \\
\text { UJIAN CL }\end{array}$ & .183 & .057 & 3.236 & .001 & & \multirow{2}{*}{$\begin{array}{l}\text { There are } \\
\text { indirect } \\
\text { effects }\end{array}$} \\
\hline B & SKP -> MTV INT & .524 & .049 & 10.676 & .000 & & \\
\hline$c^{\prime}$ & $\begin{array}{l}\text { SKP -> UJIAN } \\
\text { CL }\end{array}$ & .131 & .070 & 1.853 & .064 & & \multirow{2}{*}{$\begin{array}{l}\text { The } \\
\text { intermediary } \\
\text { factor as a } \\
\text { complement }\end{array}$} \\
\hline $\mathrm{a} \times \mathrm{b}$ & $\begin{array}{l}\text { SKP -> MTV INT } \\
\text {-> UJIAN CL }\end{array}$ & .096 & .032 & 3.010 & $.003 *$ & .038 & \\
\hline
\end{tabular}

The results in Figure 3 and Table 5 showed that indirect effects with intermediaries were significant $(\beta=.183 * .524=.096, p<.05,95 \%$ CI: .038: .167) and 95\% confidence intervals excluding zero (0), indicating that motivational intensity is an intermediate factor influencing the relationship between attitudes toward learning situations and Chinese language achievement. Therefore, the hypothesis testing of the Ha3 hypothesis accepted and the motivational intensity indirectly influencing the relationship between attitudes toward learning situations with Chinese language achievement.

Table 6

Summary of Intermediate Exam

\begin{tabular}{|c|c|c|c|c|c|c|c|c|}
\hline \multirow[t]{2}{*}{ Hypothesis } & \multirow[t]{2}{*}{ Relationship } & \multirow[t]{2}{*}{ Beta } & \multirow[t]{2}{*}{ SP } & \multirow[t]{2}{*}{$\begin{array}{l}\text { T } \\
\text { value }\end{array}$} & \multirow[t]{2}{*}{$\begin{array}{l}P \\
\text { value }\end{array}$} & \multicolumn{2}{|c|}{$\begin{array}{l}95 \% \\
\text { significantly }\end{array}$} & \multirow[t]{2}{*}{ Results } \\
\hline & & & & & & $L L$ & $U P$ & \\
\hline $\mathrm{H}_{1}$ & ORI -> MTV INT -> CL & .038 & .017 & 2.224 & .026 & .010 & .076 & Significant \\
\hline $\mathrm{H}_{2}$ & ORT $->$ MTV INT $>$ CL & .037 & .014 & 2.663 & .008 & .014 & .071 & Significant \\
\hline $\mathrm{H}_{3}$ & SKP $->$ MTV INT $>$ CL & .105 & .026 & 4.078 & .000 & .058 & 159 & Significant \\
\hline
\end{tabular}


Table 6 shows the relationship of indirect effects of integration orientation $(\beta=.151 *$ $.252=.038, p<.05,95 \%$ CI: .010: .076), instrumental orientation $(\beta=.147 * .252=$ $.037, p<.05,95 \%$ CI: .014: .071) and attitude toward learning situations $(\beta=.416 *$ $.252=.105, p<.05,95 \% C I$ : .058:. 159), showing a $95 \%$ confidence interval of zero (0), then hypothesis $\mathrm{H} 1, \mathrm{H} 2$ and $\mathrm{H} 3$ is not rejected statistically. Motivational intensity indirectly affecting the relationship between integration orientation, instrumental orientation and attitude toward learning situations with Chinese language achievement (Preacher \& Hayer, 2008). Therefore, motivational intensity has a partial indirect effect on the relationship of initiation orientation, instrumental orientation and attitude toward learning situations with positive Chinese language achievement.

\section{DISCUSSION}

The findings of this study conclude that Chinese language preservice teachers have a positive integration and instrumental orientation with Chinese language achievement. The results of this study explain that Chinese language preservice teachers choose their educational education program to get a better understanding of the Chinese culture, literature and way of life of the Chinese community. In other words, the learning of Chinese language by the preservice teacher is not only to master the context of vocabulary, vocabulary and phonetic systems, but it also involves interpersonal and intrapersonal interactions. Social Cognitive Theory (Bandura, 1977) explained that the language learning process is based on the reciprocal interaction between behaviour, environment and personal factors.

Lomicka and Lord (2016); Muge and Sumru (2018) stated that the social environment and networking is an opportunity for communication of language teachers to interact with their community. Such a situation creates a connection between social context and language where a language and culture are interrelated and cannot be separated, thus the result of social interaction is an opportunity to enhance the Chinese language proficiency (Kinginger \& Wu, 2018; Meng, Zhu \& Chao, 2018; Watson \& Ebner, 2018) in general as well as among the Chinese language preservice teachers in this study. The findings of this study are also supported by Gardner $(1985,2001)$ who stated that communication and acceptance of target language culture was one of the significant factors that increased the motivation for mastering the target language.

In addition, the positive relationship of the instrumental orientation with the achievement of the Chinese language indicates that preservice teachers are concerned with social status, career development and future educational opportunities. Findings of this study illustrate that Chinese language is one of the most important languages well and accepted by other peoples. Chinese teachers have a desire to grow their career and future professional fields. These goals will encourage them to improve their Chinese language skills. Similar finding was found in Yu and Downing's (2012) study that Asian students in Japan and Korea are instrumental-oriented in learning Chinese language with the aim of getting better jobs due to the rapid growth of China's economic need which required skilled Chinese language workers to work in Korea and Japan. On the contrary, study of Liu (2016) indicated that many participants reported having high instrumental motivation and intensity to learn Chinese in order to have a good career in future. The 
study from Tan, Chew, Hutagalung and Hamid (2019) found that preservice Chinese language teachers are instrumental-oriented with the main aim to become a teacher is to earn a stable income.

Studies by Gu and Cheung (2016); Chai, Wong and King (2016); Chiang (2018) and Hu (2019) showed that instrumental oriented motivation is the factor that determines the mastery of Chinese language. Therefore, a positive instrumental orientation is one of the main motivations for Chinese language preservice teachers to improve their Chinese language skills.

Attitudes toward learning situations are multidimensional constructs built into three subdivisions, namely, positive attitudes toward Chinese language that indicate that preservice teachers are interested and accepted Chinese language as a specialty of the teacher's educational program. Positive attitudes toward Chinese language lectures have shown that Chinese language lectures provide examples, autonomy support and good teaching for preservice teachers. Attitudes toward education programs reflect programs and learning conditions in line with career preparation in education. All three subdimensions positive attitude have shown that preservice teachers are receptive and enjoy the learning situations.

The desire and confidence of students in the learning situation will be enhanced with appropriate teaching and learning contexts (Gardner, 1985; 2001; Sumarsono, 2019). In other words, appropriate lecturers, courses, reading materials, activities and course assignments will enhance the teachers' interest in the teacher's education program (Education for All 2015 National Review Report: Malaysia, 2015) and their strong belief directly strengthens their confidence in their learning and motivates them striving for success (Fischer \& Sliwka, 2018). Gardner (2006) states that cultural and educational contexts in teacher's education institutes are two factors that determine the attitude of Chinese language preservice teachers. If the cultural context is always supportive and interactive, it will stimulate the interest of the preservice teachers in learning Chinese language while educational contexts such as educational systems, curriculum and reading materials are fun and meaningful will elevate the interest, motivation and desire of the preservice teachers to deepen the knowledge and preserve the language. Thus, a positive attitude toward the learning situation can determine the success of the preservice teacher in the education of teachers.

Integration orientations, instrumental orientations and attitudes towards positive learning situations directly enhance their interest and desire to move them toward their learning goals as stated by Wabule's (2017) in his study that attitude and motivation are factors that determine the success of preservice teacher in their future teacher's education program. According to Gardner and Lambert (1972) the orientation in learning will influence positive attitudes, thus strengthen their motivation to achieve the learning intention. Gardner $(1985,2001)$ also described motivation as an intermediary factor indirectly affecting the relationship of orientation and attitude with academic achievement. 
The findings of this study indicate that motivational intensity is an important intermediary factor. Analysis of the measurement model shows that the training teachers have a high desire and interest in learning Chinese language, and they work hard and dedicated to achieving excellent results in the examination. Therefore, motivational intensity is one of the factors that motivate the preservice teachers to succeed while the integration and instrumental orientation are the learning objectives and attitudes towards the learning situation as behaviours that accept or reject the situation encountered. The relationship of integration orientation, instrumental orientation and attitude towards positive learning situations with direct motivational intensity and hence motivational intensity directly enhances the achievement of Chinese language.

Finding in this study is similar to the study by Richter, Gendolla and Wright (2016). Liu (2017), and Chiang (2018) who found that motivational intensity can predict learning achievement of the people with strong desire to become native-like. Individual with motivational intensity are more willing to put in an effort in learning that will likely lead to better achievement and to guarantee a good career in the future. This in line with the Motivational Intensity Theory from Brehm and Self (1989) which stated that people will put an effort required to achieve the goal.

Explaining the relationships of the three relationships in this study provides an important finding. Preservice teachers are mature adults to choose their fields of study and future careers. Although the integration and instrumental orientations seem to go in different directions, both orientations influence their motivational intensity to strive for selfachievement. This explains the cultural and educational contexts of learning situations in teacher's education institutes, teachers' backgrounds such as Chinese language educational experiences, family, culture, which are different and dramatically will change the purpose of their Chinese language education selection.

\section{CONCLUSION}

In general, integration and instrumental orientation are individual goals in language learning, these two factors are equally important in determining achievement objectives. Fun learning situations directly change the individual's attitude towards learning situations. These three factors directly enhance their motivation to move towards achievement. Therefore, the relationship of orientation and attitude to language achievement is a complex network of relationships. Hence, the results of this study can be considered as a source of reference for other researchers to carry out the study based on different backgrounds, socioeconomic and educational systems to further validate the findings. This can be done by using the theoretical framework in this study towards different respondents with various socioeconomic and educational background. This is due to different background will result in different context that need further investigation. This can be done by using the theoretical framework in this study on different respondents with different socioeconomic and education background.

The methods and analysis in this research used PLS-SEM with the samples of study are limited to the teachers from education institutions. Therefore, for future studies, it is suggested to expand the study sample to institutions of higher learning in Malaysia or to 
do comparative studies with other countries. In addition, these two-stage structural models can be used to test the multidimensional constructs with formative constructs to obtain results in line with the research theory. Thus, this study could provide a source of reference for other researchers to develop new studies. Finally, the process of estimating advanced models is proposed by using the techniques of modelling observed heterogeneity and unobserved heterogeneity with the aim to compare the studies from different groups such as ethnic groups or between two particular countries.

\section{REFERENCES}

Akter, S., Fosso Wamba, S. \& Dewan, S. (2017). Why PLS-SEM is suitable for complex modeling? An empirical illustration in Big Data Analytics Quality. Production Planning and Control, 28(11-12), 1011-1021.

Bandura, A. (1977). Social learning theory. Englewood Cliffs, NJ: Prentice-Hall.

Brehm, J. W., \& Self, E. A. (1989). The intensity of motivation. Annual Review of Psychology, 40, 109-131.

Chai, C.S., Wong, L.H. \& King, R.B. (2016). Surveying and modeling students' motivation and learning strategies for mobile-assisted seamless Chinese language learning. Journal of Educational Technology \& Society, 19(3), 170-180

Chen, Y. Y., \& Yi, S. W. (2019). 泰国幼儿园学习汉语语音“声母”偏误分析及教学方 法 [Analysis of Errors in Teaching Chinese Phonetic Initials in Thai Kindergartens and Teaching Methods]. Retrieved from http://www.qiqi8.cn/article/81/sort0269/2019/20191118149236.html.

Chiang, I. C. (2018). Principles for deep knowledge and its relationships with integrative orientation, motivational intensity and English learning achievement. Linguistics and Literature Studies, 6(5), 219-227,

Clandinin, D. J., \& Husu, K. (2017). Mapping international handbook of research in and for teacher education. In D. J. Clandinin, \& J. Husu (Eds.), The SAGE handbook of research on teacher education (pp. 1-21). London: SAGE.

Cohen, J. (1988). Statistical power analysis for the behavioral sciences. Mahwah, NJ: Lawrence Erlbaum.

Creswell, J. W. (2014). Research design: Qualitative, quantitative, and mixed methods approaches. Los Angeles: SAGE publication, Inc.

Deci, E. L., \& Ryan, R.M. (2000). The "what" and "why" of goal pursuits: Human needs and the self-determination of behaviour. Psychological Inquiry, 11(4). 227-268.

Fischer, M., \& Sliwka, D. (2018). Confidence in knowledge or confidence in the ability to learn: An experiment on the causal effects of beliefs on motivation. Games and Economic Behavior, 111, 122-142.

Gardner, R. C. (1985). Social psychology and second language learning: the role of attitudes and motivation. London: Edward Arnold. 
Gardner, R. C (2001). Language learning motivation: The student, the teacher, and the researcher. Foreign Language Education, 6, 1-18.

Gardner, R.C. (2006). Motivation and second language acquisition. Retrieved from publish.uwo.ca/ gardner/SPAINTALK.pdf.

Gardner, R. C., \& Lambert, W. E. (1972). Attitude and motivation in second language learning. Rowley, MA: Newbury House.

Gendolla, G. H. E., Richter, M., \& Silvia, P. J. (2008). Self-focus and task difficulty effects on effort-related cardiovascular reactivity. Psychophysiology, 45, 653-662. doi: 10.1111/j.1469-8986.2008.00655.x.

Gu, M. Y., \& Cheung, S. P. (2016). Ideal L2 self, acculturation, and Chinese language learning among South Asian students in Hong Kong: A structural equation modelling analysis. System, 57, 14-24.

Hu, H. M. (2019). Motivation theory application in chinese language study context. Paper presented at the 1st Asia International Symposium on Arts, Literature, Language and Culture (AISALLC 2019). London: Francis Academic Press.

Macalister, J. (2017). English and language teacher education in Malaysia: An exploration of the influences on and experiences of pre-service teachers. RELC Journal, 48(1) 53-66.

Karlen, Y., Suter, F., Hirt, C., \& Merki, K.M. (2019). The role of implicit theories in students' grit, achievement goals, intrinsic and extrinsic motivation, and achievement in the context of a long-term challenging task. Learning and Individual Differences, 74, 112 .

Khalid, A. (2016). A study of the attitudes and motivational orientations of Pakistani learners toward the learning of English as a second language. SAGE Open, 6(3). doi: $10.1177 / 2158244016665887$.

Khansir, A. A., Jafarizadegan, N., \& Karampoor, F. (2016). Relation between Socioeconomic status and motivation of learners in learning English as a foreign language. Theory \& Practices in Language Studies, 6(4), 742-750.

Kinginger, C., \& Wu, Q. (2018). Learning chinese through contextualized language practices in study abroad residence halls: Two case studies. Annual Review of Applied Linguistics, 38, 102-121.

Malaysian Ministry of Education. (2015). Pelan Pembangunan Pendidikan Malaysia 2015-2025 [Malaysian Education Development Plan 2012-2025]. Kuala Lumpur.

Malaysian Ministry of Education. (2015). Education for all 2015 national review report. Kuala Lumpur: Malaysian Ministry of Education.

Lai, M. L. (2011). Cultural identity and language attitudes into the second decade of postcolonial Hong Kong. Journal of Multilingual and Multicultural Development, 32(3). 249-264. doi: 10.1080/01434632.2010.539692. 
Lai, M. L. (2013). Impacts of medium of instruction on language attitudes: A case of Hong Kong. Asia-Pacific Education Research, 22. 61-68. doi: 10.1007/s40299-0120025-1.

Lam, Y.C., Yau, Y. S., Yeo, C. E., Chew, C. K., Lee, S. P., \& Lee, V. L. (2006). Kecekapan guru pelatih dalam pengajaran dan pembelajaran membaca Bahasa Cina [Teacher proficiency in teaching and learning reading of Chinese Language]. Jurnal Penyelidikan IPBL. 7, 48-54.

Larisa Niktina, Zuraidah Mhd. Don, \& Lau, S. C. (2016). Construction and validation of a questionnaire on language learning Motivation. Зборник Института за педагошка истраживања Година, 48(2), 284-300.

Li, Y.Y. (2019). http://www.qiqi8.cn/www.qiqi8.cn > 语言文学基于汉字的特点谈对

外汉语教学中的汉字教学 [Chinese Character Teaching in Teaching Chinese as a Foreign Language Based on the Characteristics of Chinese Characters in Language and Literature]. Retrieved from http://www.qiqi8.cn/article/24/yuyanwenxue/2019/20191117149225.html.

Linyi Technician Institute. (2017). 教师积极的职业态度从何而来? [Where does the teacher's positive professional attitude come from?] Retrieved from http://www.lyjsxy.com/info/1689/2552.htm.

Liu, M. H. (2017). Motivation, motivation intensity, use of Chinese and self-rated Chinese competence. College Student Journal, 51(1), 63-78.

Lomicka, L. \& Lord, L. (2016). Social networking and language learning. In F. Farr, \& L. Murray (Eds.), Handbook of language learning and technology (pp.255-269). London: Routledge.

Mahmud, S. N. D., Nasri, N. M., Samsudin, M. A., \& Halim, L. (2018). Science teacher education in Malaysia: Challenges and way forward. Asia-Pacific Science Education, 4(8). doi: 10.1186/s41029-018-0026-3.

Meng, Q., Zhu, C., \& Chao, C. (2018). Chinese international students' social connectedness, social and academic adaptation: the mediating role of global competence. Higher Education, 75, 131-147.

Muge, S. H., \& Sumru, A. (2018). Pre-service EFL teachers' online participation, interaction, and social presence. Language Learning \& Technology, 22(1), 157-183.

Ng, P. H., Wong, S. B., Tan, K. C., Guek, Y. H., \& Lim, W. H. (2017). Kajian kes tentang tahap kecekapan lisan guru pelatih Program Diploma Pendidikan Lepasan (PDPLI) yang mendapat pengijazahan Mengajar Bahasa Cina Sebagai Bahasa Kedua dari Beijing [Case study of the level of oral proficiency of the Graduate Diploma in Education (PDPLI) trainees who gained the Degree of Teaching Chinese As A Second Language from Beijing]. Jurnal Pendidikan Bahasa, 79-86. 
Niemiec, C. P., \& Ryan, R. M. (2009). Autonomy, competence, and relatedness in the classroom: Applying self-determination theory to educational practice. Theory and Research in Education, 7(2), 133-144.

Preacher, K. J., \& Hayes, A. F. (2008). Asymptotic and resampling strategies for assessing and comparing indirect effects in multiple mediator models. Behavior Research Methods, 40(3), 879-891.

Richter, M. (2013). A closer look into the multi-layer structure of motivational intensity theory. Social and Personality Psychology Compass, 7, 1-12. doi: 10.1111/spc3.12007.

Richter, M., Gendolla, G. H. E., \& Wright, R. A. (2016). Three decades of research on motivation intensity theory. Advances in Motivation Science, 3, 149-186. doi: 10.1016/bs.adms.2016.02.001.

Sumarsono, D. (2019). Contextual teaching learning (CTL) approach towards students' self confidence in learning English; Does it have any effect? Cordova Journal of Language and Culture Studies, 10(2), 62-72.

Tan, C. T., Chew, F. P., Hutagalung, F., \& Hamid, Z. (2019). Integrative and Instrumental motivation among the Chinese language pre-service teachers. International $J$ of Academic Research in Business \& Social Sciences, 9(6), 1216-1227.

Taylor, G., Jungert, T., Mageau, G. A., Schattke, K., Dedic, H., Rosenfield, S., \& Koestner, R. (2014). A self-determination theory approach to predicting school achievement over time: the unique role of intrinsic motivation. Contemporary Educational Psychology, 39(4), 342-358.

Watson, J. R., \& Ebner, G. (2018). Language-learning strategy used by Leaners of Arabic, Chinese and Russian during study abroad. In C. Sanz, \& A. Morales-Front (Eds.), Handbook of study abroad research and practice (pp.226-246). New York: Routledge.

Wright, R. A. (2008). Refining the prediction of effort: Brehm's distinction between potential motivation and motivation intensity. Social and Personality Psychology, 2, 682-701. doi: 10.1111/j.1751-9004.2008.00093.

Yu, B. H., \& Downing, K. (2012). Determinants of international students' adaptation: examining effects of integrative motivation, instrumental motivation and second language proficiency, Edu Stu, 38(4), 457-471, doi: 10.1080/03055698.2011.643111.

Zhang, J. (2018). 开放远程教育领导力与创新研究文集 [Research Papers on Leadership and Innovation in Open Distance Education]. Beijing: Beijing Book Co. Inc.

Zhang, Y. N., Lin, C. H., Zhang, D. B., \& Choi, Y. J. (2017). Motivation, strategy, and English as a foreign language vocabulary learning: A structural equation modelling study. British Journal of Educational Psychology, 87(1), 57-74.

Zhou, Y., \& Siu A. F. (2015). Motivational intensity modulates the effects of positive emotions on set shifting after controlling physiological arousal. Scandinavian Journal of Psychology, 56(6), 613-621. 